Kim, Young-Rae \& Scott, N. (2017 Accepted Online) Network dynamics of tourism development: South Korea’s experience from 1945 to 1999 Current Issues in Tourism

\title{
NETWORK DYNAMICS OF TOURISM DEVELOPMENT IN SOUTH KOREA
}

\begin{abstract}
This study utilizes network analysis to trace the evolution of the organization of tourism stakeholders during South Korea's transition from a developing to a developed country spanning the period 1945 to 1999. Tourism stakeholder institutional development in South Korea is studied by examining changes within a network of organizations as their means and objectives evolve. Data are drawn from news articles that deal with tourism and development from 1945 to 1999, and coded into organizations, development related means and objectives. Two-mode and a one-mode metric network analysis and correspondence analysis of coded data were undertaken. The results show the dynamic nature of networks interacting among organizations along with their means and objectives. Furthermore, this study states that the "social embeddedness" of the tourism network became stronger over time, leading to further development opportunities.
\end{abstract}

Keywords: Network dynamics, Evolution of tourism development, South Korea, Tourism in transition, Social embeddedness of tourism 


\section{Introduction}

This study utilizes network analysis to trace the evolution of tourism stakeholder networks during South Korea's transition from a developing to a developed country. While prior studies have provided an in-depth description and interpretation not only on patterns of the foci and themes of tourism development (e.g, Burns, 1999; Hawkins \& Mann, 2007; Jafari, 2001), and also on conditions and factors that determine these patterns (e.g., Clancy, 1999; Dredge, 2001), they have struggled to capture the dynamics and complexity of networks of tourism organizations which have evolved over long periods of time (Hawkins \& Mann, 2007; Dredge, 2006; Milne \& Ateljevic, 2001).

This study applies a network approach to fill this research gap. A network analysis approach based on a relational perspective allows identification of the interaction of actors, and the structural relationships between organizations associated with the tourism development process and outcomes (Scott, Cooper, \& Baggio, 2008). This study considers key state-government organizations as nodes and their relationships with other actors as links, to analyze changes in the State's role. In addition, network analysis allows tourism development related means and objectives to also be considered, allowing inferences about cause and agents of network formation and transformation over time (Hay, 1998; Marsh \& Smith, 2000). Thus, tourism development here is represented by a dynamic network consisting of key organizations with their means and objectives as nodes and their relations as links over time.

South Korea has been selected for the case because it is only one of few nations that transitioned from developing to developed status in a relatively short period as described as a “century-skipping country” with industrialization, democratization, and a flourishing civic 
society accomplished within half a century (Kwon, 2006). While most studies have focused on only the development of tourism in developing countries, developed countries, or transitional countries (e.g., Bramwell \& Myer, 2007; Hall, 2004; Williams \& Balàaz, 2000), few studies have examined the role of tourism in countries ranging from developing to a developed country status.

In the remainder of this paper, we first review evolution of tourism development studies, and South Korea's tourism development context. Next the network analysis approach is discussed and adopted as the analytical viewpoint to describe and visualize the changes of the role of stakeholders, particularly government sectors in association with their development related means and objectives for the case of South Korea spanning from 1945 to 1999. Consequently analysis and results follow with some implications.

\section{Theoretical background}

\section{Evolution of Tourism Development}

After the Second World War, the growth of mass tourism and its impact both on developing and developed countries became a focal point for academic study with a variety of theoretical approaches applied. In general, early studies that applied market-oriented modernization and dependency theory debating the "good" and "bad" impacts of tourism development have become complicated and diversified in foci and themes, as well as the stakeholders and their structures under which they take place.

Burns (1999) has charted this trend from a "tourism first approach (economic growth)" to a “development first approach with social, cultural and environmental benefits.” Extending these studies, Jafari (2001) proposed four development platforms: “advocacy”, “cautionary,” “adaptancy” and “knowledge-based.” An advocacy platform promotes tourism’s economic 
value, while the cautionary platform is concerned with its negative impacts. The adaptancy platform appeared as compromise between these two standpoints, and was followed by knowledge-based approaches in order to better understand the complexities involved. In a study of the role of an institutional entity (focusing on the World Bank) and changing development themes and values, Hawkins \& Mann (2007) considered that the World Bank evolved from infrastructure-based development (Macro), and private, market-dependent development (Disengagement) toward sustainable (Sustainability) and performance (Micro) focused development.

These studies significantly contributed in identifying general trends and patterns of the foci and themes in tourism development, however they showed a limit in understanding the conditions under which specific development patterns occur, and what determines them. This research gap has been filled by the introduction of (historical) institutional political perspective. This literature uses concepts of path dependency and path creation which have been applied to deal with the durability and diversity of tourism policy over time. This approach adopts a broader perspective albeit in a specific social and state context and emphasizes the role of "institutions" embedded in path dependent and path created historical patterns (David, 1994). For example, Clancy (1999) investigated tourism development in Mexico over the past 30 years, describing tension between state and market in the process of tourism development. Dredge (2001) also reviewed the historical development of local government in New South Wales, Australia from 1900s, with respect to tourism, and discussed the influence of institutional history on how tourism is dealt with.

Evolutionary studies in tourism have provided not only general trends and patterns of the foci and themes in tourism development, but also the specific conditions and factors that 
determine these paths with an in-depth description and interpretation, drawing upon policy papers and documents along with secondary statistics. However, despite its in-depth description and interpretation of the patterns and paths, they are challenged by the complexity and dynamics of the development process where diverse multiple actors and competing values are interlinked, and interact ceaseless as they evolve (Hawkins \& Mann 2007; Dredge, 2006; Milne \& Ateljevic 2001). And also, most place-specific studies have focused on either developing countries (e.g., Chhenag 2008; Dieke , 2000), developed countries (e.g., Williams \& Shaw 1991), or transitional states moving from a planned socialist economy to a free market, such as those in Central and Eastern Europe (Bramwell \& Myer 2007; Hall 2004; Williams \& Balàaz 2000). Thus, a dynamic evolutionary perspective, in particular focusing on a country transitioning from developing to developed status, is rarely found.

\section{Network Approach and Network Transformation}

Network analysis is based on the structural view that actions are structured by patterns of relationships between actors (Barabasi, 2002). In a social context, network analysis is the result of the compromise between the functional stance, which explains that an act is decided unilaterally by structure, and behaviour theory, which insists that meaning is created through individual action. Structuration theory is the fruit of the efforts to establish a comprehensive social model that offsets the weaknesses of the structural and behavioural positions. As Giddens (1979) insisted in his structuration theory, structure is a medium as well as a result of the act that is reproduced at the same time. This analysis is represented in Giddens' discussion of the "duality of structure” (p. 69).

Network analysis provides an alternative theoretical frame to examine the interaction of actors and structural relationships in the policy-making process and public-policy outcomes. 
Traditionally, pluralism, elitism, corporatism, and the bureaucratic politics model of the policy process have focused on actors, whether individual or in a group, but do not adequately address the significance of institutional constraints or environmental factors that affect new institutional approaches. Network analysis is a useful tool to depict attributes of actors in the process of policy-making and their impacts on the policy outcome, as well as the links and interdependence between the government sector and other societal actors (Klijn, 1997; Rhodes, 2008).

In tourism, the network approach has been widely applied to investigate the complex structure between destinations and tourists associated with management and marketing (Casanueva, Gallego \& García-Sánchez, 2016). In particular, this approach has also been proven as a useful tool to identify structure, interaction and power among stakeholders associated with tourism development (Bramwell \& Meyer, 2007; Kimbu \& Ngoasong, 2013: Pforr, 2006). For example, Pforr (2006) analyzed stakeholders’ interacting and dynamic relationships in the formulation process of a particular tourism master plan in the northern territorial area in Australia. Similarly, Kimbu \& Ngoasong (2013) explored the destination stakeholders in formulating and implementing tourism policy in Cameroon, suggesting a centrally coordinated but decentralized tourism network that reaches out to all representative stakeholders when formulating and implementing tourism policies.

However, these studies typically are a static snapshot of a certain time with exception of a study in the former East Germany by Bramwell and Myer (2007) who used a policy network approach to analyze changes the role of stakeholders from a former East Germany island over 10-years. It should be noted that a network has flexible and adaptable characteristics allowing co-evolution among nodes rather than stable structural relations (Hay, 1998; Marsh \& Smith, 
2000; Scott, Cooper, \& Baggio, 2008), but is often limited in explaining change because of the complexity involved (Dredge, 2006). Methodologically, this is because of the resources, stakeholders, and the power applied in the policy process are hard to quantify (Marin \& Mayntz, 1991), resulting in difficulties of data collection. Hence, though a network may be described, how and why it evolves and transforms are not easily explained.

In spite of difficulties of collecting data on complex relationships between organizations, network theory remains useful for investigating dynamic interactions between act and structure, and recognizes actors as the active players within a structured network. Hay (1998) argues that individuals seeking to realize their objectives make a strategic assessment of the context in which they find themselves. However, that context is not fixed. Individuals learn from their actions and adjust their strategies. The context is changed by their actions and so individuals have to adjust to different contexts (Rhodes, 2008). Gardiner \& Scott (2014) argue, in the case of Gold Coast in Australia, that an individual's skill and knowledge in strategic assessment adjusting to the context is important to build and maintain a successful network. Recent theory of network resource also confirms that each organization's skills and knowledge plays a key role in conditioning mobilizing network resources to change and sustain network (Casanueva, Gallego, Castro \& Sancho, 2014).

\section{South Korea Context}

South Korea, like other newly independent countries after the Second World War, had weak human resources, institutions, and financial capacity for economic development. Even worse, South Korea became embroiled in the Inter-Korea War in 1950, only a few years after independence and after suffering more than 40 years of Japanese colonial occupation. Indeed, after the war in 1953, South Korea was a "vulnerable nation” (Woo-Cumings, 1999: 260). 
Despite its lack of financial capacity, less competitive endowed factors, and small domestic market size, the country undertook outward (export) oriented economic development policies.

Tourism in South Korea was recognized as a vehicle for national economic development enabling to contribute to export revenue and to efficiently utilize natural and cultural resources. During the 1960s and 1970s, the state undertook a number of interventions. To secure funding, the government on one hand tried to attract international aid, mostly from the USA, and on the other nationalized private banks and used them to provide capital (Kwon, 2006: 158). Key basic laws and regulations (Framework Act on Tourism, Tourism Promotion $A c t$ ) were introduced, and the first tourism department under the control of the Ministry of Transportation was created. In the 1960s, the government acquired and operated the Korea Airline Corporation, a casino, and hotels, a travel agency, and a taxi company. These were later sold to private companies through the Korea Tourism Corporation which was established in 1962. In 1970s, the government jointly funded, constructed, and operated a number of international tourist resorts (in Jeju Island, Gyeonggju, and Sorak Mountain) with the private sector. In addition, the government hosted international tourism expositions and conventions such as Pacific Asia Travel Association (PATA), American Society of Travel Agents (ASTA), as well as the Asian Games in 1986 and Olympic Games in 1988 (KTO, 2002: 73-97). The outcome was dramatic. The number of international tourists surpassed one million in 1978 and ten million in 2012, with GNP per capita increasing from \$1,500 in 1978 to $\$ 22,500$ in 2011 in real terms. South Korea became a member of the OECD in 1996.

To achieve this outcome, the South Korean government strategically and aggressively intervened to achieve economic growth while respecting the principles of private ownership and the market economy (Johnson, 1982; Woo-Cumings, 1999). A state-government has the 
autonomy to plan for the long-term national interest without having its policies disrupted by short-term corporate or working-class interests. Its actions were that of a "political entrepreneur” (Kwon, 2006: 122), although some describe it as “Korea Inc” (Mason et al., 1980: 485). Later as it introduced social and cultural pluralism, South Korea became more 'soft' and 'flexible’ requiring different roles and responsibilities (Weiss \& Hobson, 1995).

\section{Method and data}

\section{Analytical Frame and Research Questions}

The purpose of this study is to investigate the evolution in the organization of state-driven tourism development in South Korea as it transitioned from a developing to a developed status. For this, this study focus on the structural changes of the sharing power of stakeholders among public, private and other sectors such as non-profit organizations along with the changes of development related means and objectives that they have utilized. The relations between market and government have been a highlight in the study of tourism development (e.g., Bramwell \& Myer 2007; Clancy, 1999; Hall 2004; Kimbu \& Ngoasong, 2013; : Marsh \& Smith, 2000; Pforr, 2006; Williams \& Balàaz 2000), plus the means and objectives has been a key frame in explaining process and outcome of development (Dunn, 1971) guiding strategic assessment and direction of development. Three research questions are addressed:

Firstly, how have the structural characteristics of the tourism development network changed? Here structural characteristics result from interaction among organizations, and refer to the looseness or tightness of links, and if a development network is centralized or decentralized. 
Secondly, how did the organizations' relative positions and roles in the network change through the process of development? In particular, what role did the South Korea stategovernment play in the process of development?

Thirdly, what objectives and means have been used and shared by organizations in the tourism development network? Were economic-centered means and values key drivers of development as existing tourism development paths indicate? Are these values shifting toward more sustainable development paradigm?

\section{Analytical Methods}

For the first research question, network structure was characterized using network size, density, and centralization (Scott, 1991). Network density refers to the proportion of number of direct link $(\mathrm{k})$ in a network relative to the total number possible links. Density ranges from zero to one. Zero density means that all nodes are unconnected while a density of one means that every node is connected to every other node. This is common measure of how a network is densely or loosely connected ${ }^{\mathrm{i}}$. Centralization is a measure of the structure of the network as a whole and whether it has a center around which other nodes are arranged (Freeman, 1979). A centralized network will have many of its links dispersed around one or a few nodes, while a decentralized network is one in which there is little variation among the numbers of links each node possesses. The centralization of a network is calculated by dividing the proportion of observed level of the centralization by the maximum level of centralization of a network ${ }^{\mathrm{ii}}$.

For the second research question, power centrality was used to find the relative importance or influence of actors (individual organizations). This assigns relative scores to all nodes in the network based on the concept that connections to high-scoring nodes contribute more to 
the score of the node in question than equal connections to low-scoring nodes (Bonacich, 1987). For example, one is likely to be more influential if they are connected to other centers -- because they can quickly reach a lot of other actors through powerful actors ${ }^{\mathrm{iii}}$.

Thirdly, changes in focus of development (means and objectives) were examined using two-mode network analysis and correspondence analysis. The means of development includes both physical and non-physical resources that were utilized for tourism development, from construction of physical infrastructure and facilities to marketing and policy making. A two-mode network analysis that describes links between two sets of nodes at two different levels of analysis was used to examine relationships between organizations and development means. Furthermore, correspondence analysis was used to analyze the relationships between organizations and objectives. In two-mode analysis, the similarity of the actors in terms of objectives and vice versa can be examined. Correspondence analysis measures the level of correspondence between rows and columns containing categorical variables, with entries in the table representing the distances between individual rows and/or columns in a twodimensional space (Greenacre, 2007). This allows analysis of the variances among actors and events simultaneously, and mapping of the patterns of co-presence of both in the joint corresponding space. Thus, matching organizations to objectives enables an understanding of how actors are associated and by what objectives. Based on the research questions and methods, the following analytical frame is proposed in Figure 1:

$* * * * * * * *$

FIGURE 1. ANALYTICAL FRAME

ABOUT HERE 


\section{Data Sources}

Different data sources are available for use in a network analysis; historical documents such as policy papers, documentary films and secondary statistics (Dredge, 2006); direct data from interviews (Kimbu \& Ngoasong, 2013) or structured questionnaires conducted with relevant stakeholders (Pforr, 2006); or mixed of these (Bramwell \& Meyer, 2007). For this study, data was collected from a daily newspaper published from 1945 to 1999 in South Korea. Newspapers as data sources have advantages over other data sources specifically for this study. First of all, data from direct interviews or structured surveys with stakeholders are limited in their ability to capture evolution over long periods. Bramwell \& Meyer (2007) applied retrospective in-depth interview with key stakeholders over a 10-year period, but the 50-year period examined here is too long to rely on respondents' memories. Secondly, news articles fit the purpose of this study better than policy papers, and other historical documents. The purpose of the study is to examine the significant dynamic characteristics of the stategovernment organization across the development process rather than interpretation of these through analysis of policy papers and historical documents. News articles are intended to describe efficiently the "who, how, and why" of a story in a short passage which allows data to be conveniently obtained (Paranyushkin, 2010). This argument becomes more persuasive considering the long study period. In addition, news articles are a communication channel where policy makers and stakeholders interact for policy-making (Robert, 1997). In this way news stories better reflect not only objective facts but also social concerns among different stakeholders, while policy papers representing government perspective of development are 
limited and often one-sided.

To select a suitable newspaper, firstly, because of the long period of the time examined, the stories should be available in an electronic archive service. Secondly, the numbers of newspapers and articles has increased recently which influences the number of nodes and links, and hence the density and centralization measures. To avoid this only newspapers published continuously from 1945 to 1999 were considered. Thirdly, the source should be significant in terms of volume of papers sold or market share. An examination of the newspaper archive provided by Korea’s biggest portal site (www.naver.com) which accounts for $70 \%$ of internet searches as of 2012 was conducted. The Donga-Daily Newspaper was selected as it was the only one published continuously from 1945 to 1999. The Donga-Daily Newspaper has the third largest distribution of all newspapers in South Korea. Finally, it should be noted that because articles from the archive service were only available up to 1999, the study period was set to be from 1945 to 1999.

\section{Data Collection}

Data was found by using two key words to search the electronic archive: "tourism” and “development”. The resulting news articles were analyzed to identify organizations, resources, and development objectives. For example, one news article in 1960s discussed that Ministry of Transportation (organization) had designated a tourist district (means) to attract foreign tourists (objectives). An initial search identified relevant articles as well as some without relevance to this study: for example some dealt with mainly urban, rural, coastal development issues and events, where tourism was incidental. To address this, articles were included if the title contained both tourism and development. Furthermore, articles with tourism-related development as their key topic, or other equivalent development issues and events, were 
prioritized. It should be noted that occurrences of events in news articles may not represent exactly the interactions among actors and resources because it may reflect potentiality in terms of social concerns. To minimize this effect, we excluded editorials which are usually subjective opinions of events. As a result analysis of the newspaper articles selected enables the general trends and patterns of tourism network development to be determined as required by this study.

Then, it was also necessary to divide the study period into intervals to better analyze changes in the development network. The period was broken down into five intervals: 19451960 (1950s), 1961-1970 (1960s), 1971-1980 (1970s), 1981-1990 (1980s), and 1991-1999 (1990s). Three graduate students trained in the study purpose and the data collection scheme, gathered the data focusing on who (organizations), what (resources), and why (development values or objectives). This took approximately three months, from September to November 2013, and identified 1,430 news articles covering the study period and allowing lists of organizations, resources, and development values and objectives to be determined.

\section{Expert Review}

To reduce data collection bias, an in-depth focus group review session with three experts, two university professors and a senior researcher from a government sponsored research institute who each have more than 10-year experience in tourism development, was conducted to check if the organizations, means, and objectives identified accurately reflected the content of the article. In most cases organizations were relatively clear, but resources and objectives were sometimes unclear or appeared more than twice in one article. The experts were asked to exclude irrelevant news articles and select the primary means and objectives when multiple were evident, and when they were unclear, to clarify them as much as they 
could by discussing the context of the news article, and if necessary, by looking at related secondary literature. It is important to note that, development objectives were only identified for public sector organizations because articles about the private sector did not identify firm objectives. Through this process, 141 out of 1,430 articles were excluded, resulting in 1,389 news articles, and their associated organizations, resources, and objectives as shown in Table 1.

$* * * * * * * *$

TABLE 1. ORGANIZATIONS, MEANS, AND OBJECTIVES IN DETAIL

\begin{abstract}
ABOUT HERE
ABOUT HERE

Table 2 shows the number of organizations, means, and objectives over the study period that was drawn from a total of 1,389 news articles. As we see in table 2 , the number of organizations, means and objectives grows as time passes, but this simple pattern does not show the interactions and complicated relations among the subjects, means, and objectives.
\end{abstract}

TABLE 2. NUMBER OF ORGANIZATIONS, MEANS, AND OBJECTIVES ABOUT HERE

\title{
Data Structure: The Two-Mode Metric and Quasi-Network
}

In order to conduct the network analysis, a matrix was constructed consisting of the organizations in rows and the means in columns. If a newspaper article indicated a development subject (organization) used a particular type of resources (built transport 
infrastructure), a 1 was placed in the relevant cell, and if it did not, a 0 . This is called a twomode metric, expressed by [organizations $\times$ means]. However, the two-mode metric itself did not enable quantification of the interactions among organizations or creation of a network structure generated by the interactions. It was necessary to convert this two-mode metric [organizations $\times$ means] into a one-mode metric, which is expressed as [organizations $\times$ organizations]. The result is termed a quasi-network because, although the collected data does describe a one-mode network, it can still be expressed as one. In order to do this the two-mode metric was converted to a one-mode metric (Hanneman \& Riddle, 2005; Scott, 1991). The equation is expressed as $P=\left(X \times X^{\prime}\right)$. Here, $X$ is $[m \times n]$ metric (two-mode), $X^{\prime}$ is the X's transposed metric [ $\mathrm{n} \times \mathrm{m}$ ], and $\mathrm{P}$ is the quasi-network, a reconstituted square metric by $\mathrm{m}$ (actors) as $[\mathrm{m} \times \mathrm{m}]$ (one-mode).

The one-mode metric was used for research questions 1 and 2, and the two-mode metric for question 3. Table 3 provides a summary of the data structure that was used to respond to the research questions. Finally, UNICET software was used for the analysis.

TABLE 3. SUMMARY OF DATA STRUCTURE

ABOUT HERE

\section{Analysis and results}

The Table 4 shows that the relational assets of the network have dramatically increased over the period in terms of the number of organizations (nodes), the number of links (lines) 
between organizations (nodes), and their strength (weighted by the frequencies of inks). For example, the number of organizations increased from 9 nodes in the 1950s to 97 in the 1980s and then to 203 nodes in the 1990s. Accordingly, the number of links and their strength increased from 27 and 32 in the 1950s to 4,835 and 9,013 in the 1990s, respectively. In other words, relational effects are strengthened as more organizations became involved.

TABLE 4. NUMBER OF NODES AND LINKS IN THE DEVELOPMENT NETWORK ABOUT HERE

\section{Changes of Structural Characteristics}

What kind of structural shift has this development network gone through? As illustrated in Figure 2, centralization gradually declined from $70.3 \%$ in the 1950 s to $39.9 \%$ in the 1990s. In addition, density decreased from 0.38 to 0.11 during the same period. The early 1950s demonstrates a centralized structure led by a few organizations in a small and denser network but a considerable increase in the number of organizations over time has led to a decentralized structure with a loose network (Barabasi, 2002). Figure 2 shows this transformation. The connections among organizations become unclear and decentralized with the passage of time as more organizations become involved.

FIGURE 2. DENSITY AND CENTRALIZATION OF THE DEVELOPEMT NETWORK ABOUT HERE 


\section{Interactions among Organizations and their Relative Influence}

\section{Influence of Organizations over Time}

Power centrality was used to examine the relative influence of individual organizations over time. Since power centrality reveals not only the number of nodes directly connected, but also the strength of nodes that are powerfully connected, organizations higher in power values represent more influential actors. As described below in Table 5, the Ministry of Transportation had the most influential actor with power value of 2.597, followed by the United States Department of Commerce (1.099) in the 1950s. The Ministry of Transportation had a central role in tourism development after the colonial period, particularly through control of the railway system and this influence continued after national liberation. The U.S. Department of Commerce's role was important because the Korean government had to borrow funds from its ally, the U.S., to boost tourism after the inter-Korean War. The United Nations Forces (0.40) and the PATA (Pacific Asia Travel Association) (0.40) were also influential at that time. While national capability and financial ability were poor, these organizations were key leaders of tourism development. This paradigm continued into the 1960s when the Korea Tourism Organization (1.112), established in 1962 for the purpose of attracting foreign tourists, began to possess considerable influence, along with the Ministry of Transportation, which had consistently kept its position as the most influential actor indicated by the highest power values (3.183). Entering the 1990s, many other government agencies, such as the Ministry of Oceans and Fisheries and the Ministry for Agriculture, Forestry and Fisheries, along with major tourism 
development organizations (e.g., Ministry of Transportation, Ministry of Culture, Ministry of Construction, etc.), participated in many activities (Event \& Festivals, History \& Cultural Program etc.) relating to tourism development. Moreover, local governments became involved in tourism development. Few private sector organizations existed in the 1950s and those that did had very minor influence, but that influence grew as more private entities entered the sector (Keumho, Doosan, Hyundae, Lotte etc.) in the 1990s. In nongovernmental sectors, influential entities such as the Environmental Association also emerged. These results show state-government in South Korea played a key role in the process of tourism development by leading other sectors until they developed their own autonomy, especially, the private sector. These relations are more clearly revealed in the following simplified image of the development network.

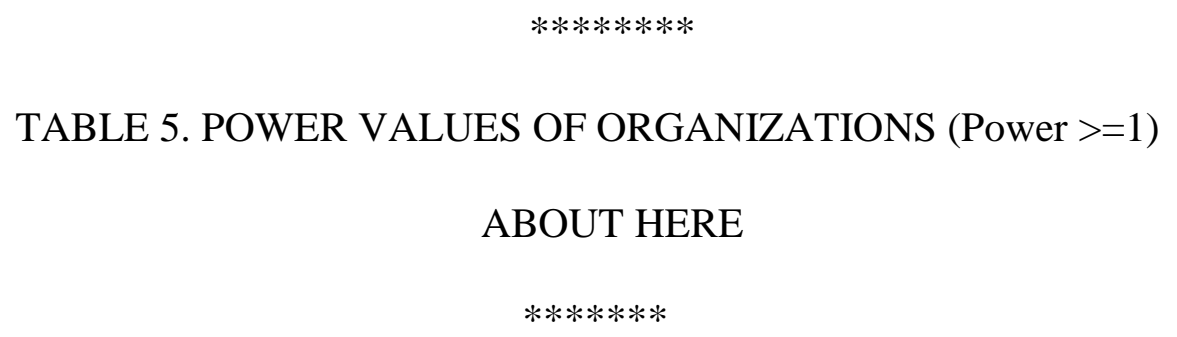

Interaction among Simplified Organizations

To reduce the interactions among organizations, the subjects were divided into the following categories: central government, local government, private sector, overseas sector, and non-governmental sector and the relative power of each calculated. As shown in Table 6, the central government's power increased from $50.6 \%$ in the 1950 s to $74.5 \%$ and $70.6 \%$ in the 1960s and 1970s respectively. Then it declined entering the 1980s and was as low as 23.3\% during the 1990s. On the other hand, the local government and private sector, each 
having $6 \%$ power in the 1950 s grew to $32.9 \%$ and $31.9 \%$ respectively in the 1990 s. In nongovernmental sectors, power was almost zero in the 1950 s and increased to $7.2 \%$ in the 1990s, a minor increase overall. The power of the overseas sector was relatively high (38.2\%) in the 1950s and then it gradually decreased. Entering the 1990s, it bounced back slightly to 5.8\%. Overall, the central government's powerful role was obvious from the 1950s to 1970s and became weaker as decades passed, while the roles of the local government, private sector, and non-governmental sector, which were almost absent in the earlier period, strengthened and diversified as the 1990s approached. Figure 3 illustrates this relation in a simplified form by using its relational strength weighted by the frequencies of links among organizations.

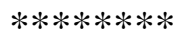

TABLE 6. POWER VALUES OF REDUCED ORGANIZATIONS

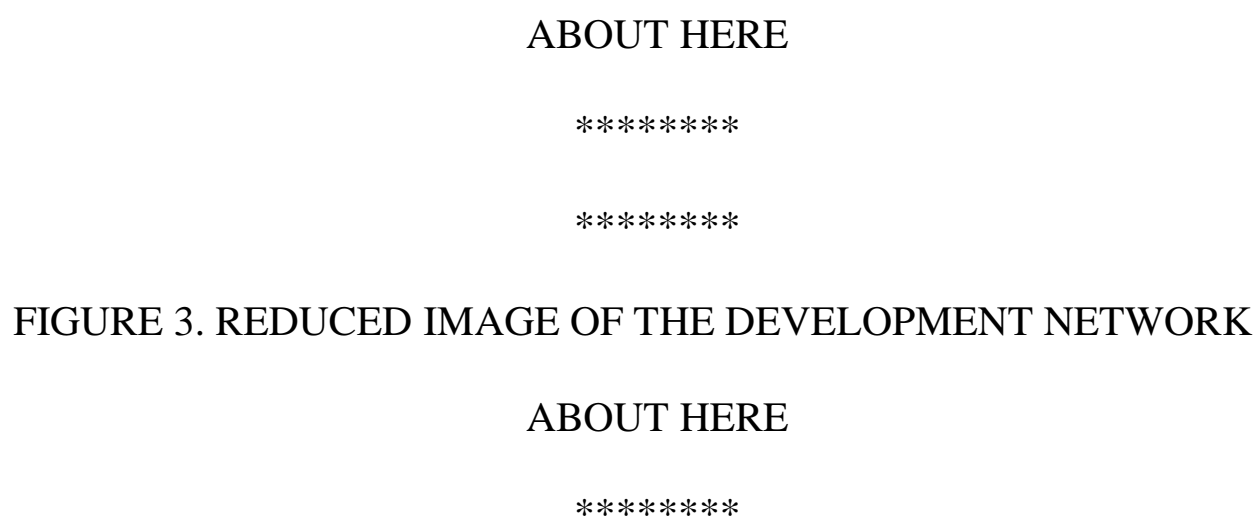

\section{Development Related Means and Objectives}

A two-mode network of organizations and means was used to examine how the development network has changed in terms of the physical and non-physical resources mobilized during the development process. Since a two-mode network does not provide power values, degree centrality (which measures centrality in terms of direct links to nodes) 
was employed. In the 1950s, the main means was accommodation (0.44 in degree centrality) followed by roads (0.33), overseas aid (0.33) and legislation (0.33) (see Table 7). In the 1960s, along with accommodation, international conventions were important (0.31 degree centrality). There were many efforts by such organizations as PATA (Pacific Asia Travel Association) to host international conferences in South Korea at this time. In the 1990s, tourist resort complexes were more frequently mentioned and also the type of resources and facilities became more diverse, encompassing the ocean, agriculture, theme parks, and recreational parks. Events and festivals (0.09), cultural and historical products (0.09), and overseas travel (0.07), also were developed in the 1990s.

The means of development is shown in Figure 4. In the 1950s and 1960s, the Ministry of Transportation (MT) along with the Korea Tourism Organization, were exclusively and directly involved with accommodation, transportation infrastructures (roads, airport), legislation, resource and facilities development (heritage, national park, etc.), overseas aid, and international convention. In particular, the MT was connected to the U.S. Government for overseas aid, and to the PATA for hosting international convention and meetings. This implies that, on the one hand, the central government exploited accommodations, airports and roads, resources and facilities to improve tourism infrastructure, and on the other hand, it also encouraged the use of foreign capital and international conventions to develop new tourism.

However, in the 1990s, the picture changes dramatically. The relationship between resources and organizations became more complicated as more diverse means and multiple subjects arose. In the 1990s, resources were shared between the central government and organizations from other sectors, in particular, local government and private sector. For example, TC (Tourist Complex) and EF (Event/Festival), which have strong degree 
centralities, were developed by diverse organizations. In sum, the earlier limited infrastructure (such as 'accommodations' and 'roads') controlled by the central government have become diverse with new actors and infrastructure such as tourist complexes, theme parks, coastal t and agricultural tourism, along with associated marketing.

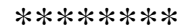

TABLE 7. TOP 10 DEVELOPMENT RELATED MEANS OVER THE PERIOD ABOUT HERE

$* * * * * * * *$

$* * * * * * * *$

FIGURE 4. A TWO-MODE NETWORK OF ORGANIZATIONS AND DEVELOPMENT RELATED MEANS

ABOUT HERE

Lastly, correspondence analysis was conducted between organizations drawn from the public sector and development objectives. Figure 5 shows in detail the changes in correspondence between organizations and objectives. In the 1950s and 1960s, the MT and the Korea Tourism Organization pursued economic growth objectives concerning foreign currency and infrastructure. In the 1970s, while eeconomy-centered growth objectives remained, new objectives such as leisure and welfare, image and brand, and conservation emerged led by the Ministry of Culture and the Korea Tourism Organization. In the 1980s, the objectives were clustered around new subjects and were shared by multiple subjects 
rather than exclusively linked to a few (indicated by a lower correspondence level). Also, a new objective, regional development appeared associated with the Ministry of Construction. In the 1990s, clustering intensified. In summary, in the earlier decades the central government led tourism development using economy-centered objectives. Later new non-economic objectives were created and responsibility for them transferred to regional level government.

$* * * * * * * *$

FIGURE 5. CORRESPONDENCE ANALYSIS OF THE ORGANIZATIONS AND OBJECTIVES

ABOUT HERE

\section{Discussion and conclusions}

\section{Summary}

This study has utilized SNA to analyze the evolution of tourism stakeholder network during South Korea's transition from developing to developed country. South Korea was chosen for its strong strategic intervention to achieve economic growth. The evolution of tourism organization was studied by analyzing changes in the relationships within a network of organizations as their development means and objectives changed. Three research questions were addressed concerning structural changes in the tourism development network, the relative position of stakeholders with special attention to the role of state-government, and the driving forces of these network changes. The results for each question are as follows: Firstly, the relational intensity of the organizations involved 
increased significantly from the 1950s to the 1990s. In the early 1950s the network had a centralized structure led by a few organizations, but over time a considerable increase in the number of organizations led to a decentralized structure. Secondly, and not surprisingly, in the beginning the tourism development network was tightly controlled by the central government, but became decentralized as local government, the private sector, the nonprivate sector, and the overseas sector emerged. State-government therefore has played a key role in the process of tourism development by leading and guiding other sectors until they developed their own autonomy, and this is especially relevant to the private sector.

Thirdly, during these structural changes in the tourism development network, there was shift from limited "hard power" (infrastructure and facility development) to more diversified and segmented infrastructure along with "soft power” (product, event and festival and marketing development) with the objectives, in general, becoming less economic-centered. The central government in cooperation with local government consistently has played a key role as controller, by leading and providing multiple organizations with resources.

\section{Implications}

Although this is a case study of South Korea's tourism development, there are a number of implications for tourism development studies generally: first, from a network perspective, there is a key role for a hub organization (in South Korea's case, the central government) connecting local government, market, and overseas sectors, to overcome a development chasm, particularly in a developing country. Second, the government's role is not static but changed over time from implementing development requirements to managing the complicated relationship among the growing numbers of organizations, and 
by implementation of governance systems. The success of this approach is rooted in the “fit-get-rich” behavior of each actor (Barbasi, 2002: 103). In the fierce competition for links amongst actors, the fittest node can grow by linking to others through "preferential attachment” (p.85). The government's role then is to lead and guide actors to be "fit” by reinforcing their relative position and power in the network. Third, the "social embeddedness” of tourism in the South Korean state and society became stronger as the country advanced, with tourism becoming linked and networked with the state in its social constitution. In turn, this increase in "social embeddedness” (Granovetter, 1992) opens up possibilities for tourism's further influence and significance, while at the same time, requiring sensitive responses to further changes. Therefore, a high level of continuous reflection on the role and significance of tourism is required.

\section{Limitations}

This study has limitations: firstly, and most importantly, in terms of data collected. Only one newspaper source was used as it was the only one available throughout the study period. In addition, the articles used in this study do not allow intention concerning tourism development to be distinguished from reality. For example, even though there were many articles on foreign aid, there were no clear description of actual foreign aid received, simply the discussion of the need for it. In addition, articles usually examined topical issues and incidents. In other words, systems and policies were mentioned less than the development of resources and facilities because the former drew less attention from the public than the latter. However, data was collected in a reliable way to reduce this bias, and also experts were asked to review the data. Since news articles are a recognized communication channel in policy making settings, the events depicted reflect both real and potential public 
concerns that allow general trends and patterns of tourism network development to be discerned. Above all, this data best fits the need to investigate the dynamics of tourism development over the 50 year study period. Newspapers conveniently and efficiently collect data on the "who, how, and why" of an event in a short article, while policy papers represent only a government perspective of development which may be limited and onesided. However, a more sophisticated data collection method would combine not only the contents of news articles but also related the secondary literature and interviews with related persons.

Secondly, the means of establishing relations among organizations were indirect and may lead to a relatively poor representation of real and direct interactions. We analyzed a quasi-network metric by transforming a two-mode into a one-mode network. So for real interactions among actors, the joint occurrences of actors that appear in news articles are suggested to be obtained for future studies. Furthermore we recommend use of weight metrics to signify the importance of events.

Thirdly, this study did not examine the period 2000 to 2010. In the 2000s, globalization and informatization accelerated in South Korea and around the globe, leading to changes in the tourism environment and interactions among actors. Therefore investigating tourism development networks in the context of globalization and an informational society would deepen understanding of this issue. Fourth, in this study there was little consideration of the institutional environment and institutional arrangements. Even though the motives of the tourism development network were examined from the perspective of means and goals, additional research is needed to review state characteristics, policy ideology, and the values and norms that have been embedded in institutional structures and practices (Dredge, 
2001). Finally, the three experts used in this study for checking of data categorization and themes were all from research institutions. In future studies a range of experts with more varied profiles should be used.

\section{Conclusion}

From a broader perspective, development refers to a term of orientation for betterment. In other words, it covers structural changes, which include processes as well as results. Even though development intends positive results at a certain point in the future, diverse factors affect the actual result. Dunn (1971) calls this the "Developmental Hypothesis,” which means that the results in the future are hypothetical, and the factors used at the present time are hypotheses for development. As the "social embeddedness" of tourism in the state and society strengthens, the possibilities of tourism increase. So the progress and results of tourism development as dialectal hypotheses are interacting endlessly among organizations, resources and objectives. This line of thought suggests states to restructure and transform their tourism development strategy and policy to “network-based tourism development”. This is underpinned by a view of tourism development as a dynamic structure with co-existing and interacting cause and effect, and processes and outcomes among actors along with objectives and resources in a spatial-temporal dimension. This perspective offers an avenue for exploring the future of tourism and a new base for tourism competitiveness, allowing for flexible and elastic response to increasing internal and external complexity of environmental changes. 


\section{References}

Barabasi, A.L. (2002). Linked: The New Science of Networks. East-Asia Publishing Company.

Bonacich, P. (1987). Power and centrality: a family of measures. American Journal of Sociology, 92, 1170-182

Bramwell, B., \& Meyer, D. (2007). Power, Tourism Policy Relations in Transition. Annals of Tourism Research, 34(3), 766-788.

Burns, P. (1999). Paradoxes in Planning Tourism Elitism or Brutalism. Annals of Tourism Research, 26(2), 329-348.

Casanueva, C., Gallego, A., \& Sancho, M. (2013) Network resources and social capital in the airline alliance porfolios. Tourism Management, 36, 441-453.

Casanueva, C., Gallego, A., Castro, I., Castro, I., \& Sancho, M. (2014) Airline alliances: Mobilizing network resources. Tourism Management, 44, 88-98.

Casanueva, C., Gallego, A., \& García-Sánchez, R. (2016). Social network analysis in tourism. Current Issues in Tourism, 19 (12), 1190-1209.

Clancy, M.J. (1999). Tourism and Development: Evidence from Mexico. Annals of Tourism Research, 26(1), 1-20.

Chhenag, V. (2008). The Political Economy of Tourism in Cambodia. Asia Pacific Journal of Tourism Research, 13(3), 281-297.

David, P. A. (1994). Why are Institutions the Carriers of History? Path Dependence and the Evolution of Conventions, Organizations and Institutions. Structural Change and Economic Dynamics, 5(2), 205-220.

Dieke, P.U.C. (2000). The Political Economy of Tourism Development in Africa. Elmsford: 
Cognizant Communication Corp.

Dredge, D. (2001). Local Government Tourism Planning and Policy-making in New South Wales: Institutional Development and Historical Legacies. Current Issues in Tourism, 4(2-4), 355-380.

Dredge, D. (2006). Networks, Conflict and Collaborative Communities. Journal of Sustain able Tourism, 14(6), 562-581.

Dunn, E.S. (1971). Economic and Social Development: A Process of Social Learning. Baltimore: The Johns Hopkins Press.

Freeman, L.C. (1979). Centrality in social networks: conceptual clarification. Social Networks 3, 41-52.

Gardiner, S., \& Scott, N. (2014). Successful Tourism Clusters: Passion in Paradise. Annals of Tourism Research, 46, 171-173.

Giddens, A. (1979). Central Problems in Social Theory. London and Basingstoke: The Macmillan Press Ltd.

Granovetter, M. (1992). Problems of explanation in economic sociology. In N. Nohria \& R. Eccles (Ed.), Networks and Organizations: Structure, Form and Action (pp. 256). Boston: Harvard Business School Press.

Greenacre, M. (2007). Correspondence Analysis in Practice. Chapman \& Hall/CRC. Hay, C. (1998). The Tangled Webs We Weave: the Discourse, Strategy and Practice of Networking. In D. Marsh (Ed.), Comparing Policy Networks. Buckingham: Open University Press.

Hall, D. (2004). Introduction. In D. Hall (Ed.), Tourism and Transition: Governance, Trans formation and Development (pp. 1-24). Wallingford: CABI 
Hanneman, R.A., \& Riddle, M. (2005). Introduction to social network methods. CA: University of California.

Hawkins, D.E., \& Mann, S. (2007). The World Bank’s Role in Tourism Development. Annals of Tourism Research, 34(2), 348-363.

Jafari, J. (2001). Research and Scholarship: The Basis of Tourism Education. The Journal of Tourism Studies, 1(1), 33-41.

Johnson, C. (1982). MITI and the Japanese Miracle. Stanford: Stanford University Press. Kimbu, A.N., \& Ngoasong, M.Z. (2013). Centralised Decentralisation of Tourism Development: A Network Perspective. Annals of Tourism Research, 40(1), 235259.

Klijn, E. (1997). Policy Networks: An Overview. In W.J. Kichkert et al. (Ed.), Managing Complex Networks. London: Sage.

KTO (2002). Korea National Tourism Organization: 40-Year History

Kwon, T.J. (2006). Century-skipping Industrialization and Democratization of Korea. Seoul: Nanam Publishing House.

Marin, B., \& Mayntz, R. (1991). Policy Networks: Empirical Evidence and Theoretical Considerations. Boulder. Colorado: Westview Press.

Marsh, D., \& Smith, M. (2000). Understanding Policy Networks: towards a dialectical approach. Political Studies, 48, 4-21.

Mason, E. et. al. (1980). The Economic and Social Modernization of the Republic of Korea. Harvard University Press

Milne, S., \& Ateljevic, I. (2001). Tourism, economic development and the global-local nexus: Theory embracing complexity. Tourism Geographies, 3(4), 369-393. 
Paranyushkin, D. (2010). Text Network Analysis. Available at http://issuu.com/deemeetree/docs/text-network-analysis

Pforr, C. (2006). Tourism Policy in the Making: An Australian Network Study. Annals of Tourism Research, 33(1), 87-108.

Rhodes, R.A.W. (2008). Policy Network Analysis. In R. Goodin, M. Moran, \& M. Rein (Ed.), The Oxford Handbook of Public Policy (pp. 425-443). Oxford University Press.

Roberts, C.W. (1997). Introduction. In C.W. Roberts (Ed.), Text Analysis for the Social Science: Method for Drawing Statistical Inferences from Texts and Transcripts. Mahwah, NJ: Lawrence Erlbaum Associates

Scott, J. (1991) Social Network Analysis. London: Sage Publication

Scott, N., Cooper, C., \& Baggio, R. (2008). Network Analysis and Tourism: From Theory to Practice. London: Multilingual Matters \& Channel View Publications.

Weiss, L., \& Hobson, J. (1995). States and Economic Development: Comparative Historical Analysis. Cambridge: Polity Press.

Williams, A.M., \& Balàaz, V. (2002). The Czech and Slovak Republics: Conceptual Issues in the Economic Analysis of Tourism in Transition. Tourism Management, 23(1), 37-45.

Williams, A.M., \& Shaw, G. (1991). Tourism and Economic Development: Western European Experiences. London: Belhaven Press.

Woo-Cumings, M. (1999). Introduction. In M. Woo-Cumings (Ed.), The Developmental State. Cornell University Press. 
Table 1. Organizations, means, and objectives in detail

\begin{tabular}{|c|c|c|c|}
\hline \multicolumn{2}{|c|}{ Category } & \multicolumn{2}{|r|}{ Description } \\
\hline \multirow{5}{*}{ Organizations } & $\begin{array}{c}\text { Central } \\
\text { Government }\end{array}$ & \multicolumn{2}{|c|}{$\begin{array}{l}\text { - central administrations and ministry, government-sponsored } \\
\text { cooperation, committees at central level, etc. }\end{array}$} \\
\hline & $\begin{array}{c}\text { Local } \\
\text { Government }\end{array}$ & \multicolumn{2}{|c|}{$\begin{array}{l}\text { - local governments, cities, local gov. (city)-sponsored cooperation, } \\
\text { committees at local level, etc. }\end{array}$} \\
\hline & Private Sector & \multicolumn{2}{|c|}{ - development \& construction company, investor, bank, etc. } \\
\hline & Overseas Sector & \multicolumn{2}{|c|}{$\begin{array}{l}\text { - overseas state \& government, overseas private company, UN, } \\
\text { tourism-related association, etc. }\end{array}$} \\
\hline & Non-gov. Sector & \multicolumn{2}{|c|}{ - civic society, academic association, interest group, etc. } \\
\hline & $\begin{array}{l}\text { Transportation } \\
\text { Infrastructure }\end{array}$ & \multicolumn{2}{|c|}{$\begin{array}{l}\text { - extension and new development of ground transportation (road, } \\
\text { railroad, express bus, etc.), airport and airline, port and cruise ship, etc. }\end{array}$} \\
\hline Development & $\begin{array}{l}\text { Resource \& } \\
\text { Facility } \\
\text { Development }\end{array}$ & \multicolumn{2}{|c|}{$\begin{array}{l}\text { - tourist site, tourist district, natural park, cultural heritage, ocean \& } \\
\text { coastal tourism, beach, hot spa site, agricultural tourism, theme park, } \\
\text { cave tourism, recreational park, accommodation \& lodging, } \\
\text { information center, golf \& sky resort, museum, convention center, etc. }\end{array}$} \\
\hline & $\begin{array}{l}\text { Product \& } \\
\text { Marketing }\end{array}$ & \multicolumn{2}{|c|}{$\begin{array}{l}\text { - exhibition \& expo, events \& festival, history \& cultural tour, night } \\
\text { tourism, shopping \& food, pilgrim, beauty \& wellbeing, interregional } \\
\text { tour course, tourist souvenirs \& gifts, DMZ (Demilitarized Zone) tour } \\
\text { course, leisure sport, sport tourism, bird observation, etc. }\end{array}$} \\
\hline & $\begin{array}{l}\text { Policy \& } \\
\text { Institution }\end{array}$ & \multicolumn{2}{|c|}{$\begin{array}{l}\text { - legislation, new policy, organization, interregional development } \\
\text { policy, etc. }\end{array}$} \\
\hline & Overseas Relation & \multicolumn{2}{|c|}{$\begin{array}{l}\text { - overseas aid, overseas investment, international convention \& } \\
\text { meetings, overseas sisterhood relations, etc. }\end{array}$} \\
\hline \multirow{5}{*}{$\begin{array}{l}\text { Development } \\
\text { Objectives }\end{array}$} & \multicolumn{2}{|c|}{ To attract foreign currency } & - To promote brand and image \\
\hline & \multicolumn{2}{|c|}{ To conserve natural \& cultural Resources } & - To strengthen competitiveness \\
\hline & \multicolumn{2}{|c|}{ To provide leisure \& welfare space } & - To build int'l tourist infrastructure \\
\hline & \multicolumn{2}{|c|}{ To construct international tourist site } & - To strengthen equal development \\
\hline & \multicolumn{2}{|c|}{ To increase local income \& quality of life } & - To improve environmental amenities \\
\hline
\end{tabular}


Table 2. Number of organizations, means and objectives

\begin{tabular}{|c|c|c|c|c|c|c|c|}
\hline \multicolumn{2}{|c|}{ Years } & 1950s & $1960 \mathrm{~s}$ & 1970s & 1980s & 1990s & Total* \\
\hline \multicolumn{2}{|c|}{ No. of News Articles } & 21 & 32 & 206 & 327 & 803 & 1,389 \\
\hline \multirow{6}{*}{ Organizations } & Central Gov. & 3 & 3 & 9 & 15 & 19 & 49 \\
\hline & Local Gov. & 1 & 7 & 13 & 20 & 62 & 103 \\
\hline & Private Sector & 1 & 0 & 5 & 48 & 77 & 131 \\
\hline & $\begin{array}{l}\text { Non-Gov. } \\
\text { Sector }\end{array}$ & 0 & 1 & 5 & 8 & 23 & 37 \\
\hline & $\begin{array}{l}\text { Overseas } \\
\text { Sector }\end{array}$ & 4 & 5 & 4 & 6 & 22 & 41 \\
\hline & Total & 9 & 16 & 36 & 97 & 203 & 361 \\
\hline \multirow{6}{*}{$\begin{array}{c}\text { Development } \\
\text { Means }\end{array}$} & $\begin{array}{c}\text { Transportation } \\
\text { Infra. }\end{array}$ & 1 & 2 & 3 & 5 & 3 & 14 \\
\hline & $\begin{array}{l}\text { Resource } \\
\text { \&Facility }\end{array}$ & 2 & 5 & 16 & 22 & 21 & 71 \\
\hline & $\begin{array}{l}\text { Product \& } \\
\text { Marketing }\end{array}$ & - & 1 & 3 & 15 & 17 & 38 \\
\hline & $\begin{array}{l}\text { Policy \& } \\
\text { Institution }\end{array}$ & 1 & 2 & 2 & 4 & 7 & 21 \\
\hline & $\begin{array}{l}\text { Overseas } \\
\text { Relation }\end{array}$ & 1 & 1 & 2 & 4 & 4 & 12 \\
\hline & Total & 5 & 11 & 26 & 50 & 52 & 144 \\
\hline \multicolumn{2}{|c|}{ Development Objectives } & 3 & 4 & 5 & 8 & 10 & 29 \\
\hline
\end{tabular}

Note: From decade to decade, some development subjects, means, and objectives overlapped. 
Table 3. Summary of data structure

\begin{tabular}{|c|c|c|c|c|c|c|}
\hline \multirow{2}{*}{$\begin{array}{l}\text { Time } \\
\text { Period }\end{array}$} & \multirow{2}{*}{$\begin{array}{l}\text { Organizations } \\
\text { (A) }\end{array}$} & \multirow{2}{*}{$\begin{array}{l}\text { Development } \\
\text { Means } \\
\text { (B) }\end{array}$} & \multirow{2}{*}{$\begin{array}{c}\text { Development } \\
\text { Objectives (C) }\end{array}$} & $\begin{array}{l}\text { One-Mode } \\
\text { Metric } \\
\text { (Research }\end{array}$ & \multicolumn{2}{|c|}{$\begin{array}{c}\text { Two-Mode Metric } \\
\text { (Research Question 3) }\end{array}$} \\
\hline & & & & {$[\mathrm{A} \times \mathrm{A}]$} & {$[\mathrm{A} \times \mathrm{B}]$} & {$[\mathrm{A} \times \mathrm{C}]^{*}$} \\
\hline 1950s & 9 & 5 & 2 & {$[9 \times 9]$} & {$[9 \times 5]$} & {$[4 \times 2]$} \\
\hline 1960s & 16 & 11 & 4 & {$[16 \times 16]$} & [16×11] & {$[10 \times 4]$} \\
\hline 1970s & 35 & 26 & 5 & [35×35] & [35×26] & {$[22 \times 5]$} \\
\hline 1980s & 97 & 50 & 8 & [97×97] & {$[97 \times 50]$} & {$[35 \times 8]$} \\
\hline $1990 \mathrm{~s}$ & 203 & 52 & 10 & {$[203 \times 203]$} & {$[203 \times 52]$} & {$[81 \times 10]$} \\
\hline
\end{tabular}

Note: The $[\mathrm{A} \times \mathrm{C}]$ metric includes organizations only from the public sector. 
Table 4. Number of nodes and links in the development network

\begin{tabular}{|c|c|c|c|c|c|}
\hline & $1950 s$ & $1960 s$ & $1970 s$ & $1980 s$ & $1990 s$ \\
\hline No. of Nodes & 9 & 16 & 36 & 97 & 203 \\
No. of Links & 27 & 58 & 160 & 918 & 4,835 \\
No. of Frequencies & 32 & 118 & 350 & 1,498 & 9,013 \\
\hline
\end{tabular}


Table 5. Power values of organizations (Power $>=1$ )

\begin{tabular}{|c|c|c|c|c|c|c|c|c|c|c|}
\hline \multirow{2}{*}{ Rank } & \multicolumn{2}{|l|}{ 1950s (N=9) } & \multicolumn{2}{|c|}{ 1960s $(\mathrm{N}=16)$} & \multicolumn{2}{|l|}{ 1970s $(\mathrm{N}=36)$} & \multicolumn{2}{|c|}{$1980 Y s(\mathrm{~N}=97)$} & \multicolumn{2}{|l|}{$1990 \mathrm{Y}(\mathrm{N}=203)$} \\
\hline & Subjects & Power & Subjects & Power & Subjects & Power & Subjects & Power & Subjects & Power \\
\hline 1 & Ministry of Transp. ${ }^{\mathrm{C}}$ & 2.597 & Ministry of Transp. ${ }^{\mathrm{C}}$ & 3.813 & Ministry of Transp. ${ }^{\mathrm{C}}$ & 3.323 & Ministry of Cons. ${ }^{\mathrm{C}}$ & 6.707 & Ministry of Culture/Sport ${ }^{\mathrm{C}}$ & 8.563 \\
\hline 2 & U.S. Gov. ${ }^{\mathrm{O}}$ & 1.099 & Korea Tourism Org. ${ }^{\mathrm{C}}$ & 1.112 & Ministry of Culture ${ }^{\mathrm{C}}$ & 3.323 & Ministry of & 5.671 & Jeju Province ${ }^{\mathrm{L}}$ & 3.985 \\
\hline 3 & & & & & Ministry of Construction ${ }^{\mathrm{C}}$ & 3.274 & Transportation ${ }^{\mathrm{C}}$ & 2.268 & Korea Tourism Org. ${ }^{\mathrm{C}}$ & 3.187 \\
\hline 4 & & & & & Korea Tourism Org. ${ }^{\mathrm{C}}$ & 1.354 & Ministry of Culture ${ }^{\mathrm{C}}$ & 1.689 & Icheon City ${ }^{\mathrm{L}}$ & 3.131 \\
\hline 5 & & & & & & & Korea Tourism Org. ${ }^{\mathrm{C}}$ & 1.060 & Ministry of Con./Transp. ${ }^{\mathrm{C}}$ & 3.005 \\
\hline 6 & & & & & & & Seoul City ${ }^{\mathrm{L}}$ & 1.048 & Gyeonggi Province ${ }^{\mathrm{L}}$ & 2.664 \\
\hline 7 & & & & & & & Chongbuk Province ${ }^{\mathrm{L}}$ & 1.011 & Keumho Development. ${ }^{\text {L }}$ & 2.661 \\
\hline 8 & & & & & & & Ssangbanguel ${ }^{\mathrm{C}}$ & 1.011 & Gangwon Province ${ }^{\mathrm{L}}$ & 2.580 \\
\hline 9 & & & & & & & Gangwon Province ${ }^{\mathrm{L}}$ & 1.010 & Chullanam Province ${ }^{\mathrm{L}}$ & 2.148 \\
\hline 10 & & & & & & & Gyeonggi Province ${ }^{\mathrm{L}}$ & & Doosan Construction ${ }^{\mathrm{P}}$ & 1.987 \\
\hline 11 & & & & & & & & & Japan Development ${ }^{\mathrm{O}}$ & 1.980 \\
\hline 12 & & & & & & & & & Seoul City ${ }^{\mathrm{L}}$ & 1.868 \\
\hline 13 & & & & & & & & & Hyundae Asan Devp. ${ }^{\mathrm{P}}$ & 1.860 \\
\hline 14 & & & & & & & & & Ministry of Agriculture ${ }^{\mathrm{C}}$ & 1.799 \\
\hline 15 & & & & & & & & & Donga Construction ${ }^{\mathrm{P}}$ & 1.604 \\
\hline 16 & & & & & & & & & Suwon City ${ }^{\mathrm{L}}$ & 1.562 \\
\hline 17 & & & & & & & & & Daewoo Development ${ }^{P}$ & 1.548 \\
\hline 18 & & & & & & & & & Jinro Group ${ }^{P}$ & 1.548 \\
\hline 19 & & & & & & & & & Ministry of Ocean/Fishery ${ }^{\mathrm{C}}$ & 1.422 \\
\hline 20 & & & & & & & & & Asian Airline ${ }^{\mathrm{P}}$ & 1.198 \\
\hline 21 & & & & & & & & & Lotte Construction ${ }^{\mathrm{P}}$ & 1.116 \\
\hline 22 & & & & & & & & & Environmental Association ${ }^{\mathrm{N}}$ & 1.073 \\
\hline
\end{tabular}

Note: C, L, P, N, and O respectively refer to central government, local government, non-government sector, private sector, and overseas sector. 
Table 6. Power values of reduced organizations

\begin{tabular}{|c|c|c|c|c|c|c|c|c|c|c|}
\hline \multirow{2}{*}{ Category } & \multicolumn{2}{|c|}{$1950 \mathrm{~s}$} & \multicolumn{2}{|c|}{$1960 \mathrm{~s}$} & \multicolumn{2}{c|}{$1970 \mathrm{~s}$} & \multicolumn{2}{c|}{$1980 \mathrm{~s}$} & \multicolumn{2}{c|}{$1990 \mathrm{~s}$} \\
\cline { 2 - 11 } & Power & $\%$ & Power & $\%$ & Power & $\%$ & Power & $\%$ & Power & $\%$ \\
\hline $\begin{array}{c}\text { Central } \\
\text { Gov. }\end{array}$ & 3.40 & $\mathbf{5 0 . 0}$ & 5.19 & 74.5 & 11.11 & 70.6 & 17.38 & 44.6 & 22.78 & $\mathbf{2 2 . 3}$ \\
\hline $\begin{array}{c}\text { Local } \\
\text { Gov. }\end{array}$ & 0.40 & $\mathbf{5 . 9}$ & 0.64 & 9.2 & 2.36 & 15.0 & 10.53 & 27.0 & 33.60 & $\mathbf{3 2 . 9}$ \\
\hline $\begin{array}{c}\text { Private } \\
\text { Sector }\end{array}$ & 0.40 & $\mathbf{5 . 9}$ & - & 0.0 & 0.67 & 4.3 & 7.09 & 18.2 & 32.59 & $\mathbf{3 1 . 9}$ \\
\hline $\begin{array}{c}\text { Non- } \\
\text { Gov. } \\
\text { Sector }\end{array}$ & - & $\mathbf{0 . 0}$ & 0.32 & 4.6 & 0.87 & 5.5 & 2.69 & 6.9 & 7.34 & $\mathbf{7 . 2}$ \\
\hline $\begin{array}{c}\text { Overseas } \\
\text { Sector }\end{array}$ & 2.60 & $\mathbf{3 8 . 2}$ & 0.82 & 11.7 & 0.72 & 4.6 & 1.28 & 3.3 & 5.90 & $\mathbf{5 . 8}$ \\
\hline Total & 6.79 & 100 & 6.97 & 100 & 15.73 & 100. & 38.97 & 100 & 102.21 & 100 \\
\hline
\end{tabular}

Note: The Power is the sum of the power values of the individual subjects in each category. The percent refers to the portion of each category in relation to the total of the power. 
Table 7. Top 10 development related means over the period

\begin{tabular}{|c|c|c|c|c|c|c|c|c|c|c|}
\hline \multirow{2}{*}{ Rank } & \multicolumn{2}{|c|}{ 1950s $(n=5)$} & \multicolumn{2}{|c|}{ 1960s (n=11) } & \multicolumn{2}{|c|}{ 1970s $(n=26)$} & \multicolumn{2}{|c|}{ 1980s $(n=50)$} & \multicolumn{2}{|c|}{ 1990s $(n=52)$} \\
\hline & Means & Degree & Means & Degree & Means & Degree & Means & Degree & Means & Degree \\
\hline 1 & RF: Accommodation & 0.44 & RF: Accommodation & 0.31 & RF: Heritage & 0.17 & RF: Tourist Complex & 0.155 & RF: Tourist Complex & 0.21 \\
\hline 2 & TI: Roads & 0.33 & OR: Int'l Convention & 0.31 & RF: Tourist Complex & 0.14 & RF: Recreational Park & 0.134 & RF: Accommodation & 0.14 \\
\hline 3 & ID: Legislation & 0.33 & ID: Legislation & 0.25 & TI: Ports & 0.14 & RF: Theme Park & 0.124 & PM: Event/Festival & 0.09 \\
\hline 4 & OR: Overseas Aid & 0.33 & TI: Airport & 0.19 & RF: Accommodation & 0.14 & RF: Accommodation & 0.093 & PM: Culture/History & 0.09 \\
\hline 5 & TI: Airport & 0.11 & TI: Roads & 0.19 & TI: Roads & 0.14 & PM: Culture/History & 0.082 & PM: Overseas Travel & 0.07 \\
\hline 6 & & & RF: Heritage & 0.13 & RF: Hot spa & 0.14 & TI: Cruise & 0.082 & RF: Theme Park & 0.07 \\
\hline 7 & & & RF: DMZ & 0.13 & RF: National Park & 0.11 & RF: Heritage & 0.072 & RF: Coastal Tourism & 0.06 \\
\hline 8 & & & RF: National Park & 0.13 & RF: Tourist District & 0.08 & RF: Accommodation & 0.072 & $\begin{array}{l}\text { RF: Agricultural } \\
\text { Tourism }\end{array}$ & 0.05 \\
\hline 9 & & & RF: Hot spa & 0.13 & RF: Recreational Park & 0.08 & RF: Coastal Tourism & 0.062 & ID: Tourism Belt & 0.04 \\
\hline 10 & & & RF: Cave & & PM: Tour Course & 0.08 & PM: Sport Tourism & 0.062 & RF: Recreational Park & 0.04 \\
\hline
\end{tabular}

Note: RF (Resources \& Facility Development), TI (Transportation Infrastructure), ID (Institutional Development), OR (Overseas Relations), PM (Product \& Marketing). 
Figure 1. Analytical frame

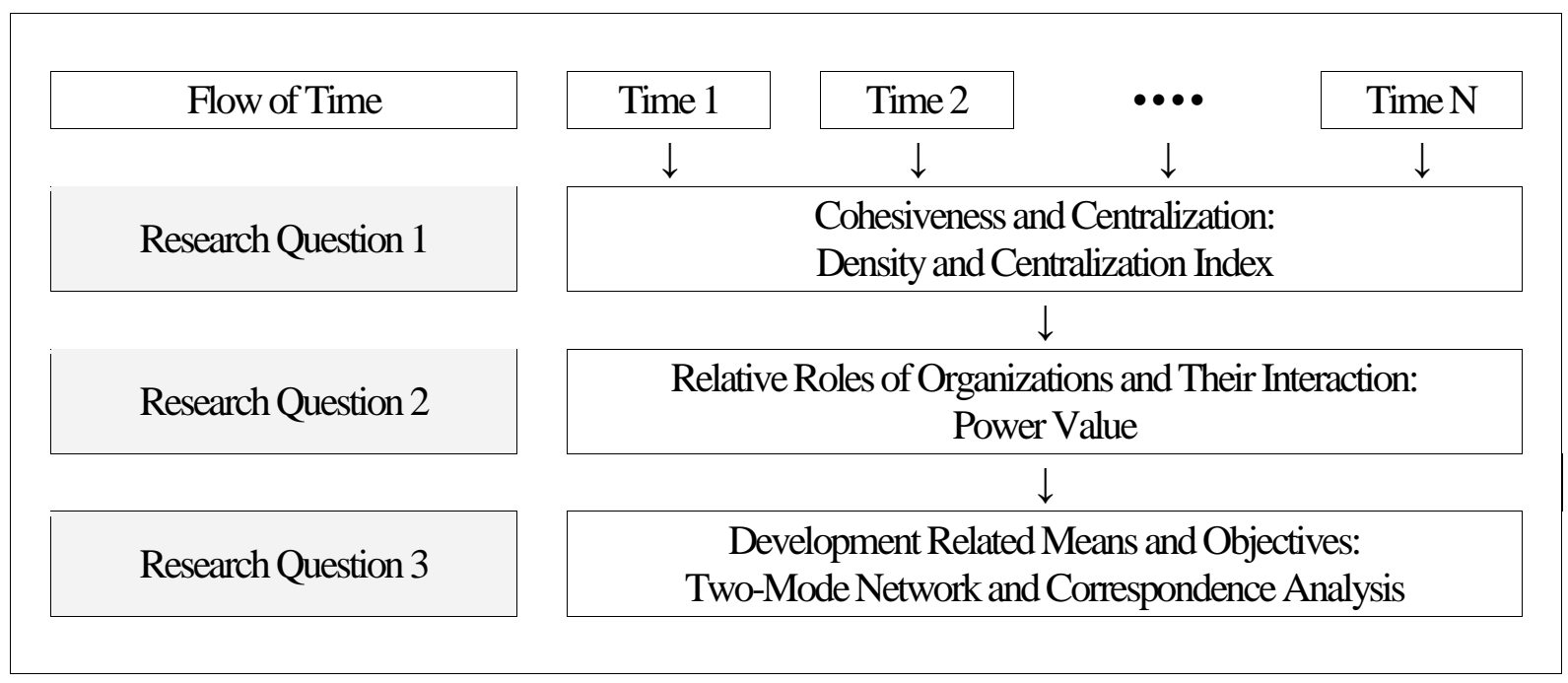


Figure 2. Density and centralization of the development network

\begin{tabular}{|c|c|c|c|c|}
\hline $1950 \mathrm{~s}$ & $1960 \mathrm{~s}$ & $1970 \mathrm{~s}$ & $1980 \mathrm{~s}$ & $1990 \mathrm{~s}$ \\
\hline $\mathrm{D}=0.38 / \mathrm{C}=70.31$ & $\mathrm{D}=0.24 / \mathrm{C}=59.55$ & $\mathrm{D}=0.13 / \mathrm{C}=45.83$ & $\mathrm{D}=0.10 / \mathrm{C}=42.65$ \\
$\mathrm{D}=0.11 / \mathrm{C}=39.87$ \\
\hline
\end{tabular}

Note : D and C respectively refer density and centralization 
Figure 3. Reduced image of the development network

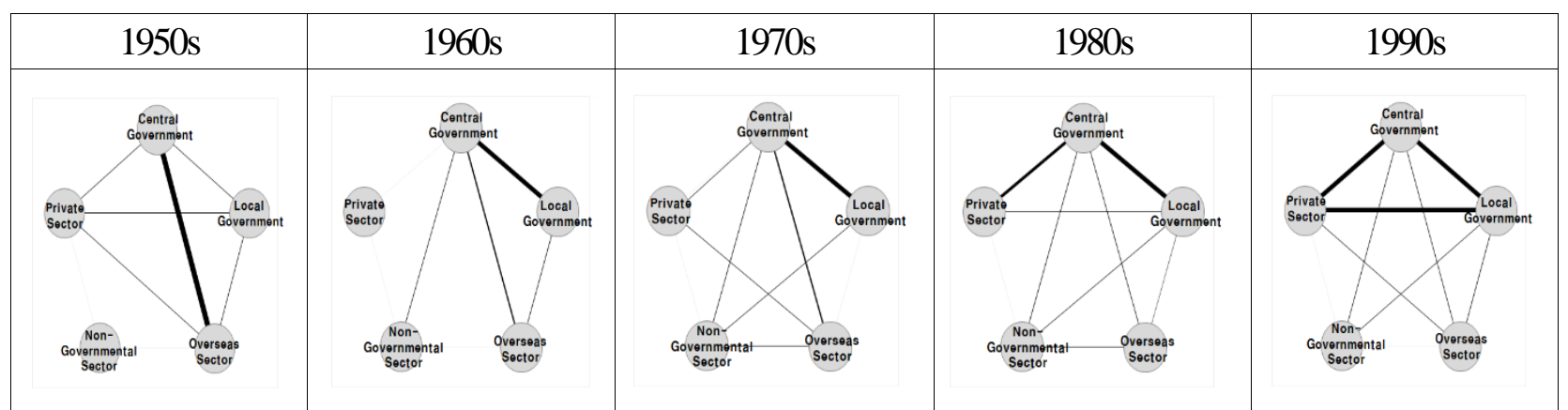

Note: The thickness of the lines refers to the network strengths, which are measured by the frequencies of the links. A strong line refers to frequencies within the upper third (>66\%) of the link frequency distribution, no line is shown for links that are within the lower third $(<33 \%)$, and a light line to links that are in the middle third $(33 \%<\mathrm{x}<66 \%)$. 
Figure 4. A two-mode network of organizations and development related means
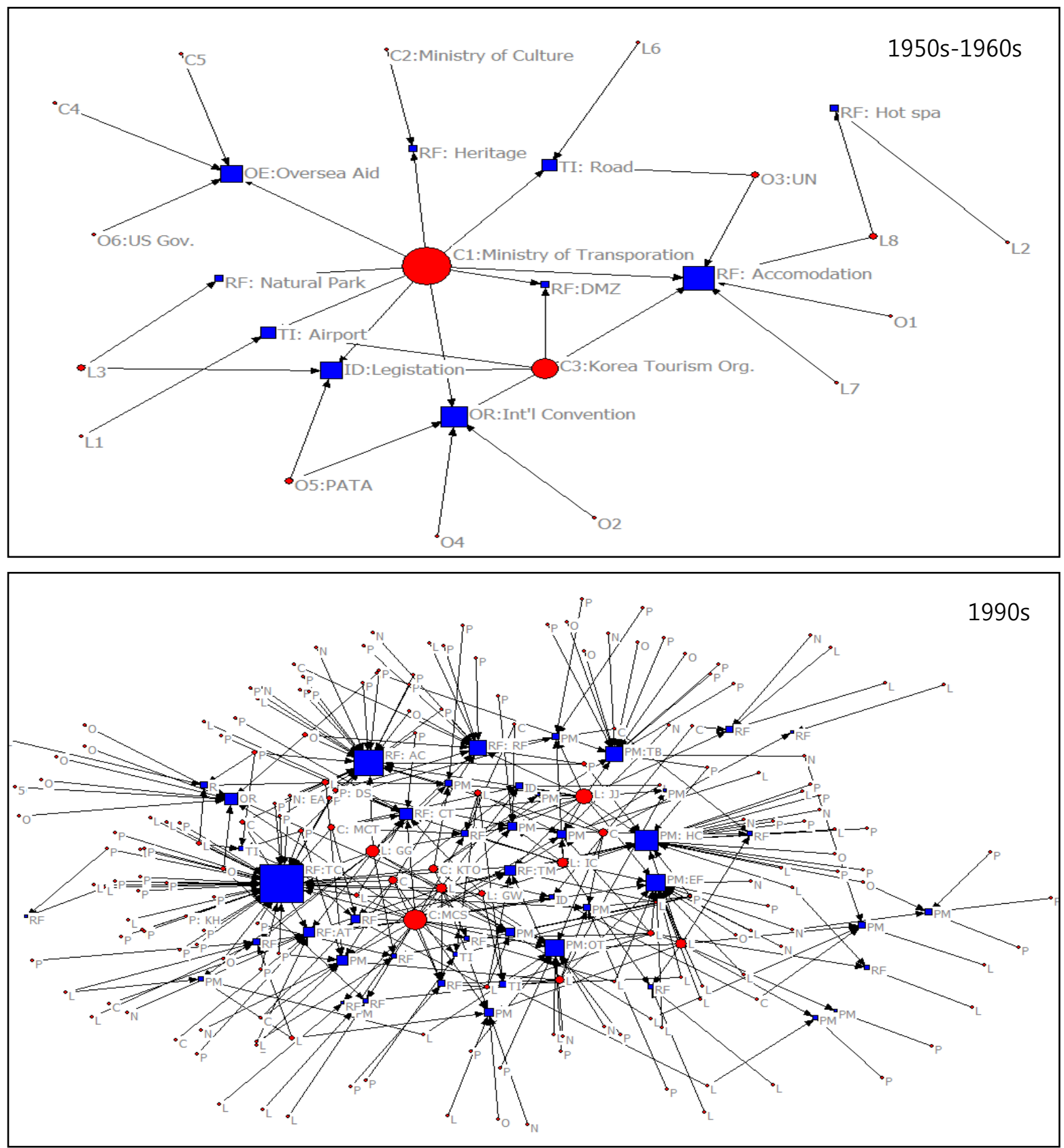

Note: 1) C, L, P, N, and O refer respectively to central government, local government, nongovernment, private sector, and overseas sector.

2) ID (Institutional Development), OR (Overseas Relations), RF (Resource \& Facility Development), PM (Product \& Marketing), TI (Transportation Infrastructure).3) AC (Accommodation), AT (Agriculture Tourism), CT (Coastal Tourism), HC (Culture/History), OT (Overseas Travel), EF (Event/Festival), RF (Recreational Facility), TB (Tourism Belt), TC (Tourist Complex), TM (Theme Park).

4) IC (Incheon City), JJ (Jeju Province), GG (Gyeonggi Province), KTO (Korea Tourism Org.), MCS (Ministry of Culture/Sport), MCT (Ministry of Construction and Transportation), DS (Doosan Dev.), SE (Seoul City). 
Figure 5. Correspondence analysis of organizations and objectives

1950s-60s: Economy-Centered Development

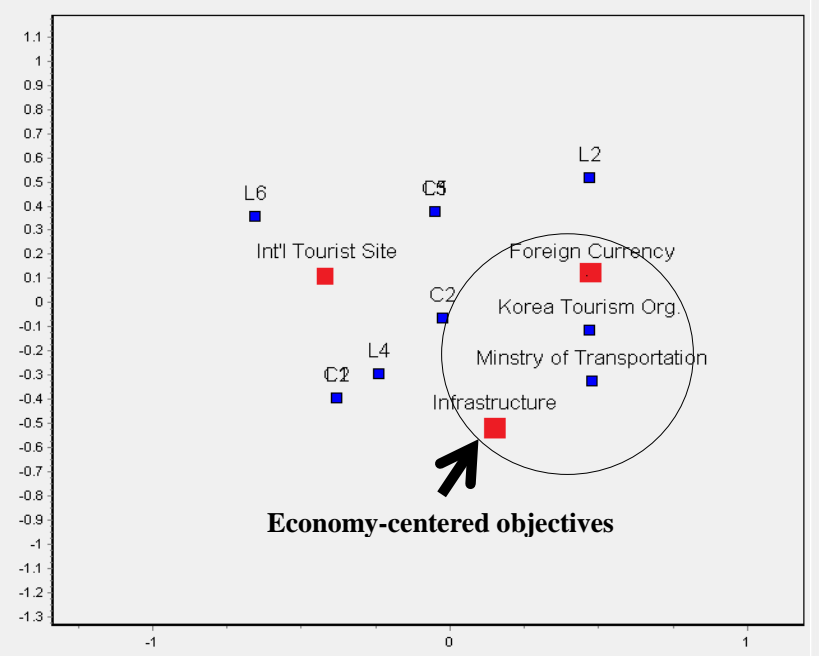

1980s: Emergence of Clustered Objectives

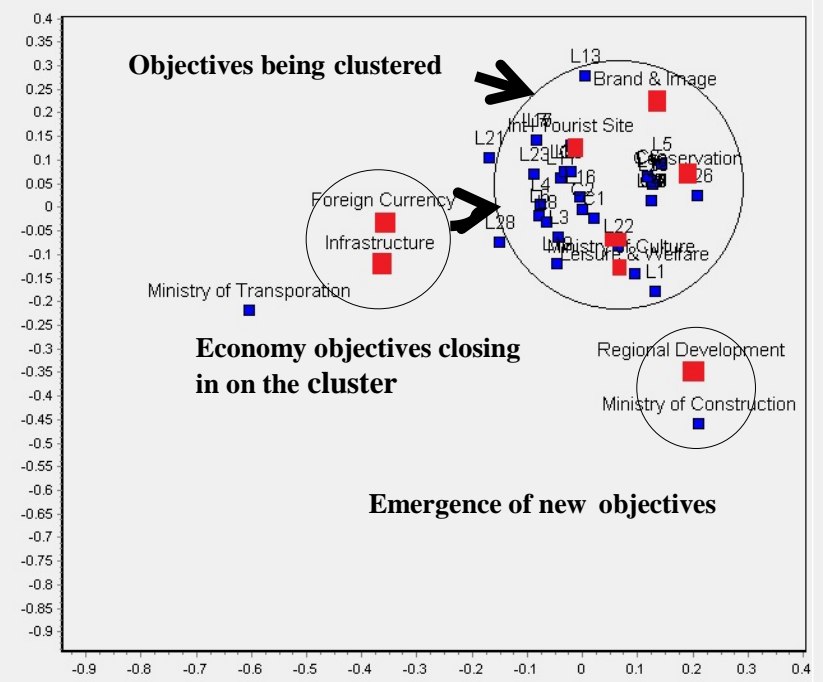

1970s: Emergency of New Objectives

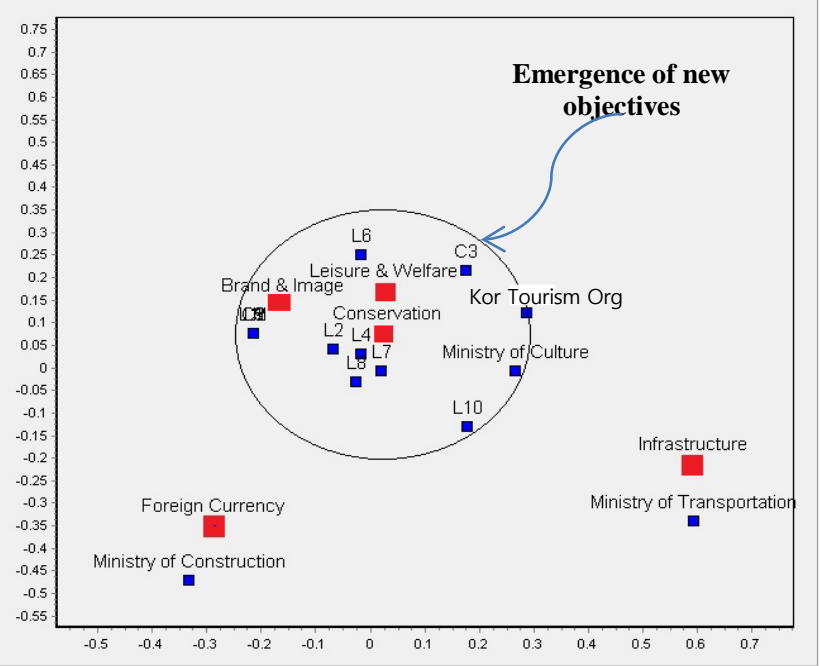

1990s: Fortification of Clustered

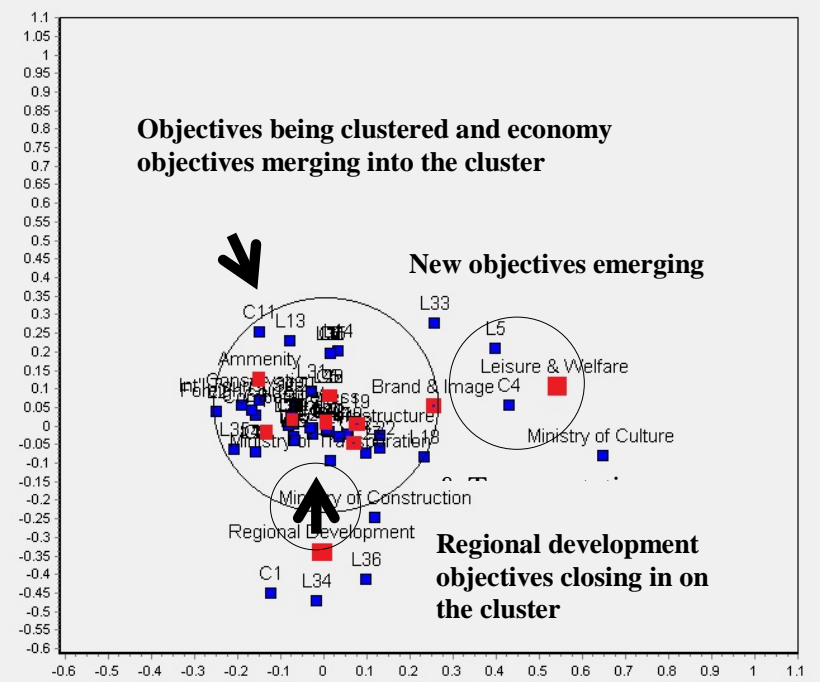

' The density (d) is expressed as follows; $d=\frac{k}{g(g-1) / 2}$, here, g: No. of Nodes, k: No. of 
Lines

ii This is usually expressed as follows; $C_{x}=\frac{\sum_{j=1}^{n} C_{x}\left(P_{*}\right)-C_{x}\left(P_{i}\right)}{\max \sum_{j=1}^{n} C_{x}\left(P_{*}\right)-C_{x}\left(P_{i}\right)}$, here, $C_{x}\left(p_{i}\right)$ is any centrality measure of point $i$, and $C_{x}\left(p_{*}\right)$ is the largest such measure in the network.

iii Power centrality is formally defined as follows: $C_{i}(\alpha, \beta)=\sum_{i}^{n}\left(\alpha+\beta C_{j}\right) R_{i j}$, here, $\alpha$ is a constant to standardize the centrality index, $\beta$ is the level of interaction. $R_{i j}$ is the adjacency matrix. 